\title{
Standardized Development and Path of the Xinjiang Corps Cooperative
}

\author{
Jia Hongbo, Wang Pengcheng \\ College of economics and management Tarim University, Alar, Xinjiang, 843300
}

Keywords: Xinjiang Corps, Cooperatives, Standardization, Development Path.

\begin{abstract}
Today, with the rapid development of social economy in our country, the rise of professional cooperatives has a very significant meaning for the marketization of agricultural products. The Corps is an important part of the agricultural development of Xinjiang, and the standardization of professional cooperatives is very important to promote the development of Corps agriculture. However, the development of Xinjiang Corps professional cooperatives is in the primary stage, so there are still many problems in the development process of cooperatives, and the farmers' knowledge level are not high, causing the lack of cooperation awareness, most farmers just have the mutual beneficial cooperation of blood and geography, this ancient sense of cooperation is very backward and lacks the modern concept of equal cooperation. Nowadays, the modern concept of equal cooperation embodies the good interaction value demand among the main bodies of the development of farmers, as well as the good ideas of commercialization of mutual benefit and winwin and complying with the rules and honesty and trustworthy . The thought breaks the antiquate thought directly, creating the precondition of standardized development for Farmer Professional Cooperatives. This paper discusses the standardized development and path of farmer's professional cooperatives, and puts forward some measures to solve the problems in the cooperative and enhance the standardized development of farmer's professional cooperatives.
\end{abstract}

\section{Introduction}

With the deepening of China's reform and opening up, Xinjiang Corps agricultural development has been increasing. It puts forward lofty goals for the construction of socialist new village at the same time. With the economic development and reform in depth, the traditional contract responsibility system in nowadays society can't match the rapid development of market economy, the traditional rural development system has led to the conflict between the farmer production and agricultural market in the rapid economic development today. From the view of development, the traditional development has restricted the development of modern agricultural economy. Therefore, the development of farmer professional cooperatives is a prerequisite for the development of modern agriculture, and the attention paid to the development of farmer professional cooperatives, is also the premise to promote the construction of new rural areas of our country.

\section{The Analysis of the Problems in Xinjiang Corps Farmers' Professional Cooperatives}

As the development of Xinjiang Corps cooperatives is still in the primary stage, some people think there is conflict between developing cooperatives and the basic management system of Corps agriculture and the conflict hinders its development; some doubt the competitively developing scene and result of various professional cooperatives currently and worry that workers form interest groups through cooperatives, which become the political force against the policy-making of the corps; some people still know a little about cooperatives, do not know how they develop; some people use administrative orders to intervene the operation and management of cooperatives too much, these knowledge is the thought shackles of the cooperatives' developing and growing, without the correct understanding of cooperatives, it can't achieve the scientific guidance.

At present stage, the non-standard operation of the farmers' professional cooperatives exists 
mainly because the cooperative decision-making is not democratic enough, the allocation of resources is irrational and the supervision work is lack. First, the insufficiency of democracy in decision is expressed in the system incompleteness of the Member Representative Assembly, Council and Board of Supervisors of the rural cooperative. Many rural professional cooperatives have the problems of system building. Though the member representative assembly, council and board of supervisors exist, the unclear distribution of liability causes the weakness of the management, resulting in the unreasonable management of the Farmers Professional Cooperative. Second, the unreasonableness of the resource distribution, insufficient management of the fund in Farmer Professional Cooperative and absence of the systematic management system cause the disorder of the fiscal account. Survey data shows that about $70 \%$ Farmers Professional Cooperatives have no accountant who specially manages the account. This leads to the management disorder of the fiscal fund because most of the funds are managed by people themselves. Third, the supervision, one of the work which should be strictly carried out by the board of supervisors, is not fully implemented. As a management organization of the interior Farmers Professional Cooperative, it effectively supervises the decisions and reasonable uses of the fiscal fund in Farmers Professional Cooperative strictly and it can avoid the change of the developmental direction. However, most of the works of the Board of Supervisors in the Farmers Professional Cooperative are not fully implemented and the Board of Supervisors is controlled by the farmers. This causes the Council' failure to play its role. Thus the lack of standardization of the supervision is caused.

In present, the Corps Cooperative is in an initiative stage. A benefit-sharing and risk-sharing interest-coalition is not formed because of the small scale, weak economic power and insufficiently close interest relationship between the members and the Cooperative. Necessary cooperation between Cooperatives is less. The Cooperative can not fully play its driving role because its ability of participating in the market competition and resisting market risk is weak. The Cooperative is hard to adapt to the fierce market competition because it mainly carries out the low-level service such as planting and breeding and is rarely involved in standardized production, product furtherprocessing and market development, etc. Some Corps develop the Cooperative by the chance of company function transformation. But the driving power of the cooperative is weak because the "relationship between company and cooperative" is not treated well and the link role between the cooperative and market is not fully played.

The follow-up funds are unable to be implemented and the demand contradiction is prominent due to the late starting, few accumulation and narrow financing channels of the cooperative. Certificate of the fixed asset in the Cooperative is incomplete and bank refuses the mortgage loan. Therefore the Cooperative can only gain the short-term (usually one year) bank loan by pledging the assets such personal real estate, car and agricultural machinery of the Cooperative members through " five-household joint guaranty". The bank limits the animal husbandry loan. what's more, considering its fund security, Commercial Bank is not willing to issue loan to Cooperative because the operation of the Professional Cooperative is unpredictable. Thus the Cooperative reports that it is hard to finance and apply for loan. This kind of situation affects the development and growth of the Cooperative.

\section{The important meaning of developing the professional cooperative by the Xinjiang Corps.}

As an extremely important part in the current operation process of the agriculture industrialization, the Farmers Professional Cooperative connects the leading enterprise with peasant household effectively and provides the services such as technological, information and sales services, etc., which not only riches the content of the agricultural industrialization operation, but also plays an active role in promoting the overall level of the agriculture industrialization.

The developing of the Farmers Professional Cooperative can effectively concentrates the local advantages and features and organizes members of the Cooperative to carry out the agricultural professional production. Thus the industrial belt and industrial clusters are formed, which lays a good foundation for the reasonable layout and scale production of the modern agriculture.

Under the circumstances of the increasingly fierce competition in agricultural products market 
and the increasing attentions paid to the quality and safety of the agricultural product, the traditional agricultural operation mode fails to adapt to the developing demand of the current market. By developing the Farmers Professional Cooperative, effectively developing its advantage of organizing carrier, organizing the cooperative members to conduct standard production and fully using the advanced technology and equipment, the agricultural production efficiency is enhanced and the agricultural product quality is guaranteed. Besides, the vital interest of the famers is protected effectively when the competitiveness of the agricultural product is enhanced.

\section{The standardized developing approaches of Xinjiang Corps Cooperation}

The establishment of the China Farmers Professional Cooperative is based on the household contract system, which is a basic regulation implemented in China for a long time. Therefore, the system construction of the new cooperative shall be based on the basic principle of taking family as the main unit and combines the national conditions of socialism in China. Farmer is the key figure in the establishment of the system and all the regulations shall be made according to farmer's will. Therefore, the Farmers Professional Cooperative shall adopt democratic management method and carry out the decision, conclusion and supervision through democratic assembly, which is the basic principle of the rural area standardization. The competitiveness of the Farmers Professional Cooperative shall be improved, the distinctive local agricultural industry shall be developed, the self-value shall be improved and the competiveness shall be promoted for protecting farmer's relevant interests.

The Farmers Cooperative is an essential way in the developmental path of socialism of China and it has an important meaning in enhancing the rural economic development and farmer's life quality. The propaganda shall be promoted so that all farmers can know their own duties and interests. In propaganda, the basic knowledge and system of the Farmers Professional Cooperative shall be promoted vigorously by ways of television media, network information and newspapers according to the local actual situations. At the same time, the successful Farmers Professional Cooperative and the local featured product shall be promoted effectively and vigorously for guaranteeing the smooth development of the Farmers Professional Cooperative.

Nowadays, all industries can not developed well without talents. As the core strength in competition, talents are essential in Farmers Professional Cooperative. We should encouraged the Farmers Professional Cooperative to actively introduce the talent.

In order to realize the systematic management of the fiscal fund in Farmers Professional Cooperative, the following things shall be conducted: first, perfect the financial institution and allocate professional management personnel; Second, distribute the work reasonably according to the actual condition, make corresponding management system and make sure the fund circulation and the recording is available for checking. Third, promote the supervision of the cash management work and make sure the timely and reasonable recording of the fund; At last, set up accounting supervision system and make sure the smooth progress of the auditing work.

First, be practically, stick to the principle of " Guidance replaces compelling, support stands for running the whole show and service substitutes for intervention" and encourage and guide workers and masses to set up corresponding professional cooperative. Guide the professional cooperative to set up and perfect the rules and regulations in these aspects such as articles of association, management, allocation, supervision and constraint, implement the regulations and systems of Cooperative strictly; Second, disclosure the finance regularly to the Cooperative members, supervise the Cooperative to establish and improve the account, standing book and record of all members, handle the relationship between the Cooperative and members based on the principle of independent accounting, responsibility for one's own profit and loss, sharing benefit and sharing risk. In accordance with the Law of Farmers Professional Cooperative, the Professional Cooperative shall return the profit according to the proportions of the volume of trade given to the Cooperative by the members, compensating for the loss, with the returning amount no less than $60 \%$ of the distributive profit. The remaining profit will allocated to the members according to the proportion of shares. 
The norm is the vitality of the Cooperative development and we should put the standardization construction of the Cooperative in a more important place and set up the specific development plan and example cooperative standard according to the reality of the Corps. Enhance cohesive force and attraction of the cooperative for the farmers and workers. Cultivate leading -level pilot cooperative and choose the excellent cooperative in the leading- level pilot cooperative to cultivate corps-level pilot cooperative. Form a cooperative system with various kinds of industries, distinctive feature and significant leadership by ways of promoting work in all areas by drawing upon the experience gained on key points.

With the continuous development of the cooperative, union is the only route which the cooperative must pass and the corps shall actively conduct the pilot work of cooperative union. The agricultural product in a regiment or even an area and a cooperative union made of the cooperatives in one industry will realize the unified producing management, product standard, brand, product sales and supply of agricultural capital, reduce cost effectively, enhance the market competitiveness and promote the Xinjiang Corps Cooperative to become bigger and stronger.

\section{Conclusion}

The rapid development of society must drive the market oriented development of the traditional agriculture. Cooperative is an effective way for the market oriented development of agriculture. The Xinjiang Corps shall keep up with the times, know the importance of the cooperative for the agricultural development of the Xinjiang Corps and realize the rapid development of the Xinjiang agriculture.

\section{Acknowledgments}

Fund program: general project of national science an technology- The study of harmonious economic development in the region around Tarim (item number : 12BJL084)

\section{References}

[1] Zhang Xiaoshan Standardized Development and Ways of Farmers Professional Cooperative[J]. Journal of Hunan Agricultural University(social science edition),2013(04)

[2] Maimaiti Simayi Study of Standardized Development and Ways of Farmers Professional Cooperative[J]. Serves of Agricultural Technology ,2017(08).

[3] Jie Yule Standardized Development and Ways of Farmers Professional Cooperative[J]. Economic management,2017(02).

[3] Guo Zhongyu, Huang Fujang The Existing Problems and its Solution of the Farmers and Workers Professional Cooperative of Xinjiang Developing and constructing Corps[J]. Farm economic management ,2015 (11).

[5] Gaojun. Developing the Modern Professional Cooperative with the features of Xinjiang Corps[J]. Promotion of the Agricultural MachineryTechnology,2015(11). 